\title{
Suberose: A propósito de um caso de pneumonia de hipersensibilidade aguda
}

Suberosis: Case report of acute hypersensitivity pneumonia

Rev Port Imunoalergologia 2019;27 (4):335-336

Cristiana Ferreira', Arminda Guilherme', Sofia Neves²

' Serviço de Imunoalergologia

${ }^{2}$ Serviço de Pneumologia

Hospital Vila Nova Gaia/Espinho

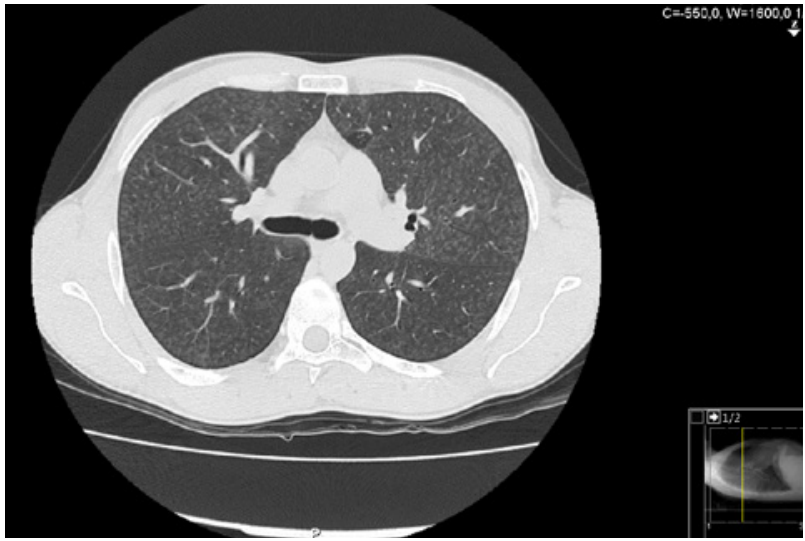

Figura I. TC de alta resolução evidenciando um padrão micronodular com distribuição centrilobular bilateral

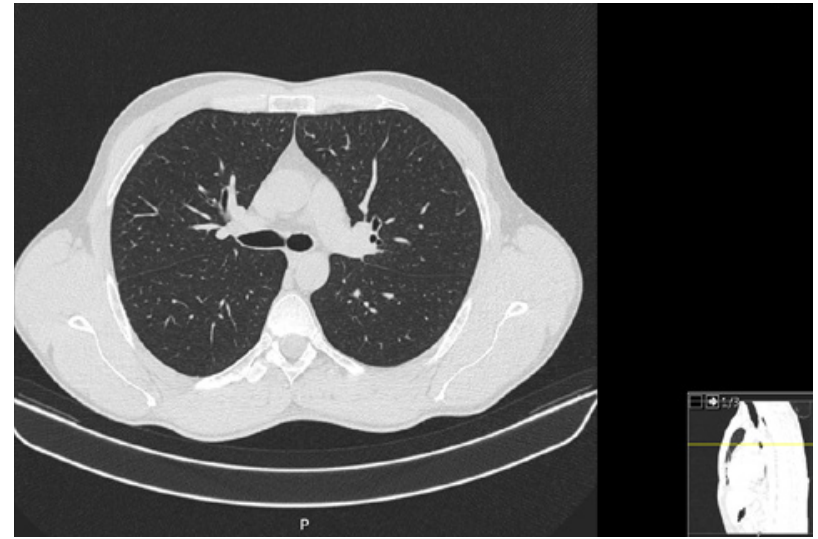

Figura 2. TC de alta resolução com desaparecimento de anormalidades radiológicas quatro meses depois 


\section{COMENTÁRIO}

$\mathrm{H}$ omem de 32 anos, rabaneador numa corticeira desde há 15 anos. Observado em consulta por episódios recorrentes de tosse com expetoração mucopurulenta, pieira, sudorese, febre e mialgias com três anos de evolução. Melhoria sintomática com o afastamento do local de trabalho. Exame funcional respiratório (EFR) revelou padrão restritivo ligeiro e defeito ligeiro da difusão do CO. A tomografia computorizada de alta resolução (TCAR) evidenciou um padrão micronodular com distribuição centrilobular traduzindo patologia intersticial (Figura I). Lavado broncoalveolar completo compatível com alveolite linfocítica intensa com relação CD4/CD8 baixa. IgG para Penicillium chrysogenum, Cladosporium herbarum, Mucor racemosus, Alternaria alternata: $142 \mathrm{mg} / \mathrm{l}$ e Micropolyspora faeni, Thermoactynomyces vulgaris, Aspergillus fumigatus: $162 \mathrm{mg} / \mathrm{l}$. Após suspensão da atividade profissional, quatro meses depois, repetiu TCAR e EFR com franca melhoria imagiológica (Figura 2) e funcional. A análise conjunta destes exames permitiu chegar ao diagnóstico de pneumonite de hipersensibilidade aguda. A suberose é uma doença do interstício pulmonar provocada pela exposição repetida ao pó e bolor da cortiça. O diagnóstico de suberose começa com a suspeição clínica, seguindo-se a realização de exames complementares de diagnóstico. $O$ tratamento consiste na evicção antigénica com resolução espontânea do quadro.

\section{COMMENT}

A 32-year-old man, worker in cork industry for 15 years presented productive cough, sweating, fever and myalgias with 3 years of evolution. Symptomatic improvement when he was outside work, during vacations and weekends. Pulmonary function testing (PFT) revealed a restrictive pattern and a slight reduction of diffusing capacity of the lung for carbon monoxide (DLCO). High-resolution computed tomography (HRCT) demonstrated bilateral centrilobular fine nodules (Figure I). Bronchoalveolar lavage fluid (BALF) revealed lymphocytosis with a low CD4+/CD8+ ratio. IgG Penicillium chrysogenum, Cladosporium herbarum, Mucor racemosus, Alternaria alternata: $142.00 \mathrm{mg} / \mathrm{l}$, Micropolyspora faeni, Thermoactynomyces vulgaris, Aspergillus fumigatus: $162.00 \mathrm{mg} / \mathrm{l}$. After suspending his professional activity, four months later all opacities have disappeared according to the control CT scan (Figure 2) and PFT were normal. A diagnosis of acute hypersensitivity pneumonitis was established. Suberosis is a type of hypersensitivity pneumonitis caused by repeated exposure to cork proteins and molds. The diagnosis of suberosis begins with clinical suspicion followed by complementary diagnostic tests. Eviction to the antigen exposure is critically important in its management with spontaneous resolution.

Contacto:

Cristiana Ferreira

cristianascferreira@gmail.com 